\title{
Aqueous extracts of husks of Plantago ovata reduce hyperglycaemia in type 1 and type 2 diabetes by inhibition of intestinal glucose absorption
}

\author{
J. M. A. Hannan ${ }^{1}$, L. Ali ${ }^{2}$, J. Khaleque ${ }^{2}$, M. Akhter ${ }^{2}$, P. R. Flatt ${ }^{1}$ and Y. H. A. Abdel-Wahab ${ }^{1}$ \\ ${ }^{1}$ School of Biomedical Sciences, University of Ulster, Coleraine BT52 1SA, Northern Ireland, UK \\ ${ }^{2}$ Department of Pharmacology, Biomedical Research Group, BIRDEM, Dhaka-1000, Bangladesh
}

(Received 2 December 2005 - Revised 1 March 2006 - Accepted 21 March 2006)

\begin{abstract}
Plantago ovata has been reported to reduce postprandial glucose concentrations in diabetic patients. In the present study, the efficacy and possible modes of action of hot-water extracts of husk of $P$. ovata were evaluated. The administration of $P$. ovata $(0.5 \mathrm{~g} / \mathrm{kg}$ body weight $)$ significantly improved glucose tolerance in normal, type 1 and type 2 diabetic rat models. When the extract was administered orally with sucrose solution, it suppressed postprandial blood glucose and retarded small intestinal absorption without inducing the influx of sucrose into the large intestine. The extract significantly reduced glucose absorption in the gut during in situ perfusion of small intestine in non-diabetic rats. In $28 \mathrm{~d}$ chronic feeding studies in type 2 diabetic rat models, the extract reduced serum atherogenic lipids and NEFA but had no effect on plasma insulin and total antioxidant status. No effect of the extract was evident on intestinal disaccharidase activity. Furthermore, the extract did not stimulate insulin secretion in perfused rat pancreas, isolated rat islets or clonal $\beta$ cells. Neither did the extract affect glucose transport in 3T3 adipocytes. In conclusion, aqueous extracts of $P$. ovata reduce hyperglycaemia in diabetes via inhibition of intestinal glucose absorption and enhancement of motility. These attributes indicate that $P$. ovata may be a useful source of active components to provide new opportunities for diabetes therapy.
\end{abstract}

Plantago ovata: Glucose absorption: Gastrointestinal motility: Insulin secretion: Insulin action

Diabetes mellitus is a major cause of disability and hospitalization resulting in significant financial and social burden across the world (Foster, 1994). Although a sub-group of type 2 patients can be managed by diet alone, most individuals with diabetes require oral hypoglycaemic drugs or insulin. However, the effectiveness of drug therapy is limited and is often associated with complications and side-effects including hypoglycaemia (Davis \& Granner, 1996). Many patients fail to respond to oral antidiabetic agents and consequently need insulin therapy. In recent years, the popularity of complementary medicine has increased. Dietary measures and traditional plant therapies as prescribed by Ayurvedic and other indigenous systems of medicine, are used commonly in India (Warier, 1995). WHO has also recommended evaluation of the effectiveness of these plants in situations where there is a lack of safe modern drugs (Upadhayay \& Pandey, 1984). The antihyperglycaemic activity of a large number of these plants has been evaluated and confirmed in different animal models (Swanston-Flatt et al. 1991).

Plantago ovata (Psyllium) is found in India, Iran, northern Africa and Pakistan. It has been used traditionally for constipation, diarrhoea, haemorrhoids, irritable bowel syndrome, weight loss, obesity, high cholesterol and diabetes (Mehta et al. 1976). The seeds and the husks contain high levels of fibre and become highly gelatinous when soaked in water. This stimulates bowel evacuation and thus has been used widely as a fibre supplement in the treatment of constipation
(Chopra et al. 1986). According to a report by the American Diabetic Association, fibre improves the control of blood glucose and delays glucose absorption and hyperinsulinaemia (Chandalia et al. 2000). Studies on the effect of $P$. ovata husk in patients with type 2 diabetes found that it can reduce the postprandial rise of glucose and insulin levels significantly (Wolever et al. 1991; Anderson et al. 1999). The plant has been shown also to reduce carbohydrate absorption (Abraham $\&$ Mehta, 1988). It delayed gastric emptying and reduced colon transit time in man (Washington et al. 1998).

It is well known that type 2 diabetes is associated with a significantly increased risk of macrovascular disease (Laakso \& Lehto, 1997). Supplementation of the diet with soluble fibre or consumption of a high-fibre diet has been shown to lower total serum cholesterol and triacylglycerol in type 2 diabetic patients (Vinik \& Jenkins, 1988). P. ovata also reduced total cholesterol and LDL-cholesterol in animals (Fernandez et al. 1995; Terpstra et al. 2000) and in man (Romero et al. 1998; Burton \& Manninen, 1982).

The present study was undertaken to evaluate the antidiabetic properties of the husk of $P$. ovata and to explore the possible mechanisms of action. The effects of the plant on glucose homeostasis, carbohydrate digestion, absorption and gastrointestinal motility were investigated. Possible effects on insulin secretion were also evaluated using different in vitro systems and glucose uptake was studied using 3T3 adipocytes. 


\section{Materials and methods}

\section{Plant materials and preparation of extract}

Husks of $P$. ovata were collected from a local market in Bangladesh (north-eastern region) and botanically authenticated with voucher specimens deposited in the National Herbarium, Bangladesh. For the preparation of hot-water extract, $P$. ovata husk ( $200 \mathrm{~g}$ ) was boiled with distilled water (44 litres) for $1 \mathrm{~h}$ and filtered. The filtrate was centrifuged at $4000 \mathrm{rpm}(1750 \mathrm{~g})$ and the supernatant was collected and concentrated by rotary evaporator. The extract was finally freeze-dried ( $21 \mathrm{~g})$.

\section{Animals and induction of type 1 and 2 diabetes}

Long-Evans male rats were bred at BIRDEM (Bangladesh) and maintained on $12 \mathrm{~h}$ light-dark cycle at $21 \pm 2^{\circ} \mathrm{C}$. A standard pellet diet and water were supplied ad libitum. The overall nutrient composition of the diet was $36.2 \%$ carbohydrate, $20.9 \%$ protein, $4.4 \%$ fat and $38.5 \%$ fibre with metabolizable energy content of $11.8 \mathrm{MJ} / \mathrm{kg}(2820 \mathrm{kcal} / \mathrm{kg})$. Type 1 diabetes was induced by a single intraperitoneal injection of anaesthetized, fasted rats $(180-220 \mathrm{~g})$ with $65 \mathrm{mg}$ streptozotocin/kg body weight dissolved, immediately before use, in $0.5 \mathrm{M}$ citrate buffer ( $\mathrm{pH} 4 \cdot 5)$. The blood glucose level was checked on the seventh day after injection of streptozotocin. Animals having blood glucose levels $>20 \mathrm{mmol} / \mathrm{l}$ were considered to be diabetic. Type 2 diabetes was induced by a single intraperitoneal injection of rats $48 \mathrm{~h}$ old with $90 \mathrm{mg}$ streptozotocin $/ \mathrm{kg}$ body weight (Bonner-Weir et al. 1981). Experiments were carried out 3 months after injection. During the experimental periods, the diabetic rat models did not receive any therapy to control diabetes other than aqueous extracts of $P$. ovata. In addition, the mean fasting plasma glucose concentrations recorded in type 1 and type 2 diabetic rat models prior to acute studies were 9.0 (SEM 0.5) and 26.6 (SEM 1.0) $\mathrm{mmol} / \mathrm{l}$, respectively ( $n 6 ; P<0 \cdot 001$ ).

\section{Effects of aqueous extracts of Plantago ovata on glucose homeostasis}

To evaluate effects on fasting blood glucose, the hot-water extract of $P$. ovata $(0.5 \mathrm{~g} / \mathrm{kg}$ body weight $)$ was suspended in water and administered by gavage to $12 \mathrm{~h}$ fasted rats. The control group received an equal volume of deionized water. Serum was separated by centrifugation and stored at $-20^{\circ} \mathrm{C}$ until analysed. Effects on glucose tolerance were similarly evaluated by administration of hot-water extracts together with glucose $(2.5 \mathrm{~g} / 10 \mathrm{ml}$ per kg body weight) after a $12 \mathrm{~h}$ fast. Control rats received glucose solution alone. To evaluate chronic effects of $P$. ovata, type 2 diabetic rats were given hot-water extract $(0.5 \mathrm{~g} / \mathrm{kg}$ body weight by gavage) twice daily for $28 \mathrm{~d}$. Control rats were similarly administered water alone $(10 \mathrm{ml} / \mathrm{kg}$ body weight). Blood samples were collected from the cut tip of the tail at the times indicated in the figures. Serum was separated by centrifugation and stored at $-20^{\circ} \mathrm{C}$ until analysed.

\section{Effects of Plantago ovata on sucrose absorption from gastrointestinal tract}

Type 2 diabetic and control rats were fasted for $12 \mathrm{~h}$ before receiving a $50 \%$ sucrose solution by gavage $(2.5 \mathrm{~g} / \mathrm{kg}$ body weight) with or without hot-water extract of $P$. ovata $(0.5 \mathrm{~g} /$ $\mathrm{kg}$ body weight). Blood samples were obtained from the tail vein before and 30, 60, 120 and 240 min after sucrose administration for the determination of glucose. Some of the rats were killed at these timings. The gastrointestinal tract was excised and divided into six segments: the stomach; the upper $20 \mathrm{~cm}$, middle and lower $20 \mathrm{~cm}$ of the small intestine; the caecum; the large intestine. Each segment was washed out with acidified ice-cold saline and centrifuged at $3000 \mathrm{rpm}(1000 \mathrm{~g})$ for $10 \mathrm{~min}$. The resulting supernatant was boiled for $2 \mathrm{~h}$ to hydrolyse the sucrose followed by neutralization with $\mathrm{NaOH}$. Blood glucose and the amount of glucose liberated from residual sucrose in the gastrointestinal tract were measured. The gastrointestinal sucrose content was calculated from the amount of liberated glucose (Goto et al. 1995).

\section{Effects of Plantago ovata on intestinal glucose absorption}

An intestinal perfusion technique (Swintosky \& Pogonowskawala, 1982) was used to study the effect of $P$. ovata on intestinal absorption of glucose in $36 \mathrm{~h}$ fasted non-diabetic rats anaesthetized using sodium pentobarbital $(50 \mathrm{~g} / \mathrm{kg})$. The hotwater extract of $P$. ovata $(10 \mathrm{mg} / \mathrm{ml}$, equivalent to $0.5 \mathrm{~g} / \mathrm{kg})$ suspended in Krebs Ringer buffer, supplemented with glucose $(54 \mathrm{~g} / \mathrm{l})$, was passed through pyloris and the perfusate was collected from a catheter inserted at the end of ileum. The control group was perfused with Krebs Ringer buffer supplemented with only glucose. Perfusion was carried out at a rate of $0.5 \mathrm{ml} / \mathrm{min}$ for $30 \mathrm{~min}$ at $37^{\circ} \mathrm{C}$. The results were expressed as percentage of absorbed glucose, calculated from the amount of glucose in solution before and after the perfusion.

\section{Effects of Plantago ovata on intestinal disaccharide activity and gastrointestinal motility}

The hot-water extract of $P$. ovata was administered by a gavage $(0.5 \mathrm{~g} / \mathrm{kg}$ body weight $)$ to $20 \mathrm{~h}$ fasted rats. After $60 \mathrm{~min}$, the rats were killed and the small intestine was isolated, cut longitudinally, rinsed with ice-cold saline and homogenized with $10 \mathrm{ml}$ saline $(0.9 \% \mathrm{NaCl})$. Aliquots of homogenate were then incubated with $40 \mathrm{mmol} / \mathrm{l}$ sucrose at $37^{\circ} \mathrm{C}$ for $1 \mathrm{~h}$. Disaccharidase activity was calculated by glucose concentration converted from sucrose as $\mu \mathrm{mol} / \mathrm{mg}$ glucose per protein per h. For determination of gastrointestinal motility, the hot-water extract of $P$. ovata was given by gavage $(0.5 \mathrm{~g} / \mathrm{kg}$ body weight $)$ to $12 \mathrm{~h}$ fasted non-diabetic rats. After $60 \mathrm{~min}, \mathrm{BaSO}_{4}$ milk $(10 \% \mathrm{w} / \mathrm{v}$ in $0.5 \%$ sodium carboxymethyl cellulose suspension) was similarly administered. After a further $15 \mathrm{~min}$, the rats were killed and gastrointestinal tract was excised. The distance traversed by $\mathrm{BaSO}_{4}$ milk was measured and expressed as a percentage of the total length of small intestine.

\section{Effects of Plantago ovata on insulin secretion and action}

Long-Evans rats (180-250 g) were used for studies on insulin secretion from perfused pancreas and isolated islets. Pancreatic perfusion studies were carried out at $37^{\circ} \mathrm{C}$ according to the method of Giroix et al. (1983). Pancreatic islets were isolated by collagenase digestion (Moskalewski, 1969) and hot-water 
extract of $P$. ovata was tested at $30 \mu \mathrm{g} / \mathrm{ml}$. BRIN-BD11 cells were used to evaluate the effects on insulin secretion from a pure cellular population. The production and characteristics of these cells have been described in detail elsewhere (McClenaghan et al. 1996). The glucose concentrations employed for pancreatic perfusion and islet studies were 3 and $11 \mathrm{mmol} / \mathrm{l}$. For insulin release studies using BRIN-BD11 cells, the acute tests were carried out at $5.6 \mathrm{mmol} / \mathrm{l}$ glucose. The effects of $P$. ovata on cellular glucose uptake also employed a cell line, namely 3T3-L1 cells obtained from the American Type Culture Collection (ATCC, Manassas, VA, USA). Glucose uptake was measured by adaptation of the method of Frost \& Lane (1985).

\section{Analysis}

Glucose was measured by the glucose oxidase phenol and 4amino-antipyrine method, HDL-cholesterol, NEFA and total antioxidant status were determined by enzymatic colorimetric methods using commercial kits from SERA PAK (Berkeley, CA, USA). Serum fructosamine was determined by a colorimetric method using a kit from Boehringer Mannheim GmbH (Mannheim, Germany). Insulin was measured by ELISA using a rat insulin kit from Crystal Chem Inc. (Downers Grove, IL, USA). Hepatic glycogen was extracted (Vander Vries, 1954) and measured at $650 \mathrm{~nm}$ in a microwell plate ELISA reader (EL 340; Bio-Tek, Winooski, VT, USA). Platelet aggregation was measured using a Chrono Log Lumi aggregometer (Chronolog Corp., Havertown, PA, USA) linked to a potentiometric recorder. Results are presented as means and standard deviations. Groups of data were compared using unpaired Student's $t$ test and Mann-Whitney U-test where appropriate. Where data were collected over a number of time-points, they have been analysed using repeated measures ANOVA, with Bonferroni adjustment to ensure an overall error rate of $5 \%$. One-way ANOVA was performed and pair-wise comparisons to the control group were made using Dunnett's test to preserve an overall error rate of $5 \%$. Differences were considered significant at $P<0.05$.

\section{Results}

Acute and chronic effects of Plantago ovata on serum glucose and metabolic parameters

Administration of $P$. ovata in the fasting state did not exert any hypoglycaemic action in either non-diabetic or diabetic (type 1 and type 2 ) rats (Fig. $1(\mathrm{~A}-\mathrm{C})$ ). When given simultaneously with an oral glucose load, $P$. ovata significantly opposed the rise of serum glucose at $30 \mathrm{~min}(P<0 \cdot 01)$ in controls, type 1 and type 2 diabetic rats (Fig. 1(D-F)). Oral administration of sucrose caused a prominent elevation of serum glucose with a peak at $30 \mathrm{~min}$ in both normal and type 2 diabetic rats (Fig. 2). The rise in blood glucose after sucrose loading was suppressed significantly by $P$. ovata at 30 and $60 \mathrm{~min}$ in both groups of rats $(P<0 \cdot 05)$. As shown in Table 1 , oral administration of $P$. ovata to type 2 diabetic rats for $28 \mathrm{~d}$ lowere fructosamine levels with significantly $(P<0 \cdot 05)$ compared with controls. No significant differences were observed in fasting levels of serum glucose, insulin and total antioxidant status. However, $P$. ovata significantly lowered total cholesterol $(P<0 \cdot 05)$, triacylglycerol $(P<0.05)$ and NEFA $(P<0 \cdot 01)$ levels. There were no significant differences in HDL, platelet aggregation, pancreatic insulin or hepatic glycogen content compared with the control (Table 1).

\section{Effects of Plantago ovata on sucrose absorption from the gastrointestinal tract}

Administration of hot-water extract of $P$. ovata $(0.5 \mathrm{~g} / \mathrm{kg})$ with the sucrose load in non-diabetic rats increased the residual intestinal sucrose content significantly $(P<0.01)$ in the middle part of the intestine at $30 \mathrm{~min}$ (control $v$. P. ovata, 8.5 (SD 3.0) $\mathrm{mg} v .18 .8(\mathrm{SD} 6.2) \mathrm{mg}$ ) and in the entire small intestine at $60 \mathrm{~min}$ (upper $20 \mathrm{~cm}, 4.8$ (SD 2.6) $\mathrm{mg} v .15 .1$ (SD 6.8) mg; middle, 0.61 (SD 6.15) mg v. 15 (SD 7.0) mg; lower $20 \mathrm{~cm}, 1.1$ (SD 0.6) $\mathrm{mg} v .1 .9$ (SD 1.3$) \mathrm{mg}$ ) and $120 \mathrm{~min}(1.6$ (SD 0.1.0) mg v. 5.5 (SD 2.8) mg, 4.7 (SD 1.9) mg $v .12 .1$ (SD 4.2) $\mathrm{mg}$ and 0.7 (SD 0.32) $\mathrm{mg} v .1 .6$ (SD 0.64) $\mathrm{mg}$ ). The total sucrose content remaining in the gastrointestinal tract was increased significantly in $P$. ovata-treated rats compared with normal controls $(P<0.05$; Fig. 3(A)). Similar effects of $P$. ovata were observed in type 2 diabetic rats after a sucrose load $(P<0 \cdot 05$, at 60 and 120 min; Fig. 3(B)).

\section{Effects of Plantago ovata on intestinal glucose absorption}

As shown in Fig. 4, intestinal glucose absorption in non-diabetic rats was almost constant during $30 \mathrm{~min}$ of perfusion. Addition of $P$. ovata to the glucose perfusate resulted in a substantial decrease in intestinal glucose absorption during the whole experimental period $(P<0 \cdot 01)$.

\section{Effects of Plantago ovata on intestinal disaccharidase activity and gastrointestinal motility}

There were no significant differences on disaccharidase (sucrase) activity between non-diabetic controls and rats supplemented with $P$. ovata (data not shown). In contrast, the plant extract significantly increased gastrointestinal motility by $20 \%$, assessed using $\mathrm{BaSO}_{4}$ milk, compared with non-diabetic controls $(P<0.001)$.

\section{Effects of Plantago ovata on insulin secretion and action}

Hot-water extract of $P$. ovata did not affect insulin secretion from the perfused rat pancreas, isolated rat islets or clonal pancreatic $\beta$ cell line, BRIN-BD11, at a range of concentrations tested $(8,40,200,1000$ and $5000 \mu \mathrm{g} / \mathrm{ml}$ ) (data not shown). Similarly, $P$. ovata did not affect glucose transport in 3T3 adipocytes in the absence or presence of $10^{-9} \mathrm{M}$-insulin (data not shown).

\section{Discussion}

Plantago ovata is commonly used in India, Pakistan and Bangladesh for the treatment of constipation, irritable bowel syndrome and diabetes. However, a very limited number of studies have evaluated antihyperglycaemic effects of the husk (Anderson et al. 1999). In the present study, the effects of hot-water extract of Plantago ovata on glucose homeostasis 
(A)

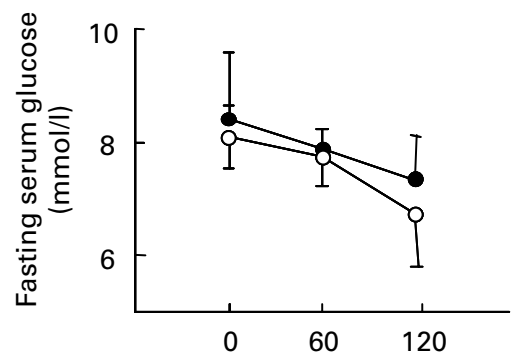

(B)

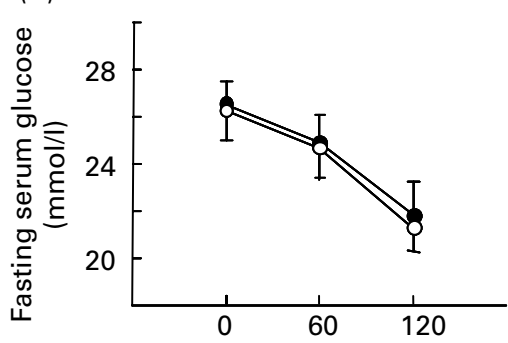

(C)

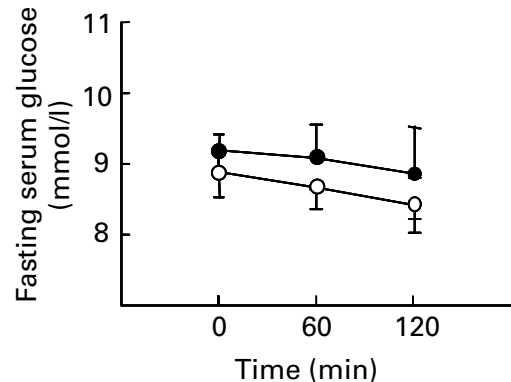

(D)

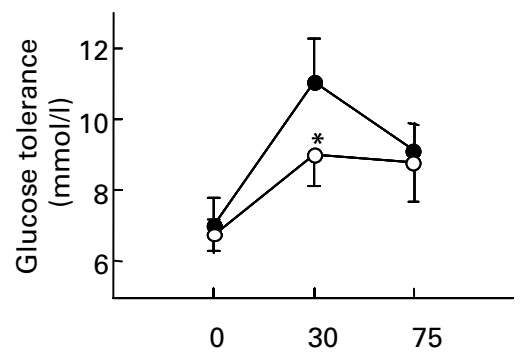

(E)

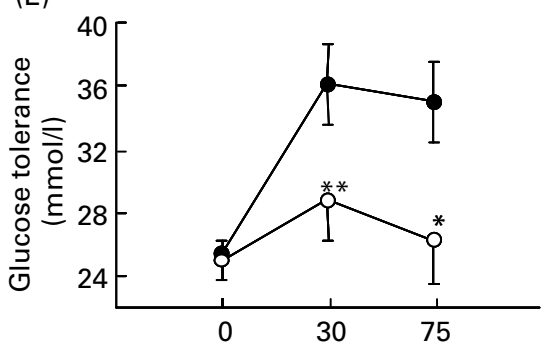

(F)

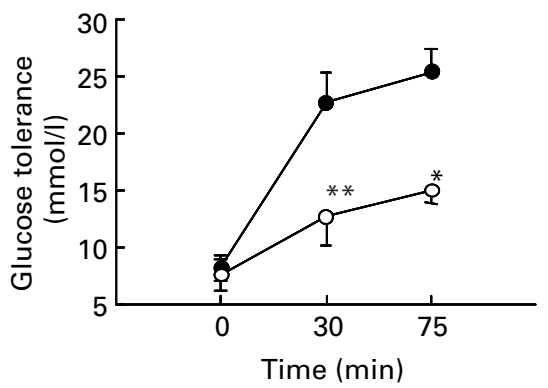

Fig. 1. Effects of hot-water extracts of Plantago ovata on fasting serum glucose (A-C) and glucose tolerance (D-F) in non-diabetic (A, D), type 1 diabetic (B, E) and type 2 diabetic (C, F) rats. Fasting rats were given glucose $(2.5 \mathrm{~g} / \mathrm{kg}$ body weight) without $(\bullet)$ or with $(O)$ hot-water extract of $P$. ovata $(0.05 \mathrm{~g} / \mathrm{kg}$ body weight). For details of procedures, see p. 132. Values are means with standard deviations depicted by vertical bars $(n 6)$. Mean values were significantly different from those of the respective control group (repeated measures ANOVA, adjusted using a Bonferroni correction): ${ }^{*} P<0 \cdot 05 ;{ }^{\star \star} P<0 \cdot 01$.

were evaluated using a number of model in vivo and cellular systems.

Postprandial hyperglycaemia is undesirable as it increases glycosylation products, such as methylglyoxal, which play a role in the development of diabetic vascular disease (Thornalley, 1996). Acute elevation of glucose also increases coagulation (Ceriello et al. 1996) and results in multiple disturbances in endothelial cell function (Haller, 1997; King et al. 1997). The present serum fructosamine data in type 2 diabetic rat models receiving $P$. ovata extract daily clearly demonstrate that the plant exhibits antihyperglycaemic properties in the previous 2-3 weeks. Unlike fasting glucose, which did not change serum fructosamine, it represents a stable measure that reflects the recent glycaemic environment.

When administered with an oral glucose load, $P$. ovata markedly improved glucose tolerance in normal rats and established models of type 1 and type 2 diabetes. The antihyperglycaemic action of the extract in severely insulin-deficient type 1 diabetic rats argues against the action being mediated by increased insulin secretion. This was confirmed by lack of the effect of $28 \mathrm{~d}$ treatment of type 2 rats on circulating insulin as well as in vitro insulin secretion studies with isolated perfused rat pancreas, isolated rat islets and clonal BRIN-BD11 cells. Furthermore, $P$. ovata did not affect glucose transport in 3T3 adipocytes. This indicates that enhancement of insulin sensitivity or glucose-lowering 'insulin-like' action is also unlikely to account for antidiabetic activity of the plant extract.

Since the glucose-lowering effect of $P$. ovata was clearly evident when simultaneously administered with glucose, inhibition of glucose absorption in the gut is a likely contributor to the mechanism of action (Lempcke, 1987; Vinik \& Wing, 1990). It is well known that high-fibre diets improve glucose tolerance in diabetes (Fukagawa et al. 1990; Nutall, 1993). This effect may be due to retarded gastric emptying, increased intestinal transit, or modification of the secretion and action of digestive enzymes (Hannah \& Howard, 1994). In the present study, we assessed various effects of $P$. ovata extract on carbohydrate digestion and absorption in the gut. When the extract was given by gavage simultaneously with sucrose solution to non-diabetic and type 2 diabetic rats, it suppressed the resulting rise of serum glucose and increased the unabsorbed sucrose content throughout the small intestine. These effects do not appear to be associated with inhibition of intestinal 


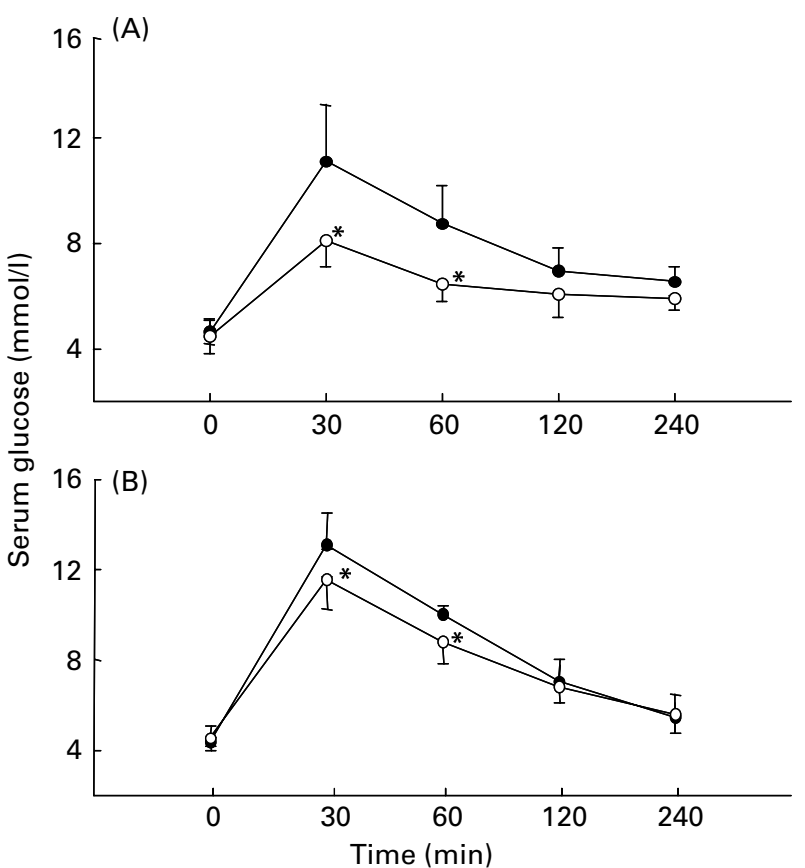

Fig. 2. Effects of hot-water extract of Plantago ovata on serum glucose after sucrose load in non-diabetic (A) and type 2 diabetic (B) rats. Rats were fasted for $20 \mathrm{~h}$ and administered a sucrose solution by gavage $(2.5 \mathrm{~g} / \mathrm{kg}$ body weight) without $(\bullet)$ or with $(\bigcirc)$ hot-water extract of $P$. ovata $(0.5 \mathrm{~g} / \mathrm{kg}$ body weight). For details of procedures, see p. 132. Values are means with standard deviations depicted by vertical bars $(n 6)$. Mean values were significantly different from those of the respective control group (repeated measures ANOVA, adjusted using a Bonferroni correction): ${ }^{*} P<0.05$.

disaccharidase activity, although loss of competitive effects on enzyme activity cannot be entirely ruled out. This suggests that reduction of sucrose absorption was not related to the enzyme activity as observed with $\alpha$-glucosidase inhibitors (Hanefeld et al. 1991). However, the extract significantly reduced glucose absorption during in situ perfusion of small intestine. Thus, limitation of the glycaemic excursion by $P$. ovata is at least partly due to the retardation of carbohydrate absorption, which is consistent with the suggestion of Abraham \& Mehta (1988). Interestingly, several early in vitro studies suggest that high concentrations of metformin also inhibit glucose absorption (Caspary \& Creutzfeld, 1971; Lorch, 1971). The effects of $P$. ovata extract on gastrointestinal motility were also evaluated in non-diabetic rats. A significant increase in motility was noted, which supports the findings of others (Chopra et al. 1986; Marteau et al. 1994). Thus, a component of the antihyperglycaemic activity of $P$. ovata is probably due to increased motility of the gastrointestinal tract.

Dyslipidaemia, particularly low levels of HDL-cholesterol and high levels of total cholesterol, triacylglycerols and NEFA, is an important risk factor for atherosclerotic complications of diabetes (Laakso \& Lehto, 1997). Elevated NEFA levels also lead to pancreatic $\beta$ cell lipid overload, dysregulation of insulin secretion (Prentki et al. 1992; Zhou \& Grill, 1995) and apoptotic cell death (Maedler et al. 2001; Lupi et al. 2002). Raised NEFA contributes to many of the other major metabolic abnormalities in diabetes including decreases in glucose transport, glycogen synthesis and glucose oxidation (DeFronzo et al. 1992). Thus, a key goal in the management of diabetes is correction of dyslipidaemia (Vague, 2003). In the present study, administration of extract of $P$. ovata for $28 \mathrm{~d}$ lowered total cholesterol, triacylglycerol and NEFA levels in type 2 diabetic rats. The present findings are consistent with other investigations (Everson et al. 1992; Fernandez et al. 1995). In the present chronic study, there was no significant effect on glycogen deposition in the liver, which may reflect lack of effect of $P$. ovata on insulin secretion.

In conclusion, the present study has demonstrated that the hot-water extract of the husk of $P$. ovata exerts strong antihyperglycaemic actions in type 1 and type 2 diabetes by

Table 1. Effects of $28 \mathrm{~d}$ treatment with Plantago ovata on glucose homeostasis and other metabolic features in type 2 diabetic rats $(n 12) \dagger$

(Values are means and standard deviations)

\begin{tabular}{|c|c|c|c|c|c|c|c|c|}
\hline \multirow[b]{3}{*}{ Parameters } & \multicolumn{4}{|c|}{ Day 0} & \multicolumn{4}{|c|}{ Day 28} \\
\hline & \multicolumn{2}{|c|}{ Control } & \multicolumn{2}{|c|}{ P. ovata } & \multicolumn{2}{|c|}{ Control } & \multicolumn{2}{|c|}{ P. ovata } \\
\hline & Mean & SD & Mean & SD & Mean & SD & Mean & SD \\
\hline Glucose (mmol/lol per I) & $7 \cdot 0$ & 0.9 & $7 \cdot 3$ & 0.8 & $7 \cdot 1$ & 0.6 & 6.7 & 0.9 \\
\hline Fructosamine $(\mu \mathrm{mol} / \mathrm{l})$ & $132 \cdot 9$ & $22 \cdot 0$ & $150 \cdot 5$ & $20 \cdot 2$ & $157 \cdot 8$ & $14 \cdot 8$ & $129 \cdot 4^{*}$ & $14 \cdot 1$ \\
\hline Insulin $(\mathrm{ng} / \mathrm{ml})$ & 0.44 & 0.09 & 0.41 & 0.07 & 0.46 & 0.14 & 0.47 & 0.08 \\
\hline Pancreatic insulin (nmol/g tissue) & & & & & 0.79 & 0.24 & 0.81 & 0.51 \\
\hline Liver glycogen $(\mathrm{g} / 100 \mathrm{~g})$ & & & & & 1.69 & 0.37 & 1.63 & 0.56 \\
\hline TAS $(\mathrm{mmol} / \mathrm{l})$ & 0.8 & 0.1 & 0.9 & 0.1 & 0.8 & 0.1 & 0.9 & 0.2 \\
\hline Cholesterol (mg/dl) & 710 & 110 & 702 & 104 & 712 & 101 & $627^{\star}$ & 62 \\
\hline Triacylglycerol (mg/l) & 513 & 84 & 562 & 52 & 495 & 98 & $404^{*}$ & 61 \\
\hline HDL-cholesterol (mg/l) & & & & & 399 & 82 & 447 & 68 \\
\hline NEFA $(\mathrm{mmol} / \mathrm{l})$ & 0.7 & 0.2 & 0.7 & 0.1 & 0.6 & $0 \cdot 1$ & $0.5^{\star}$ & 0.1 \\
\hline Platelet aggregation (\%) & & & & & $40 \cdot 1$ & 3.6 & $36 \cdot 3$ & $4 \cdot 7$ \\
\hline
\end{tabular}

TAS, total antioxidant status.

Mean values were significantly different from those of the control group (unpaired $t$ test): ${ }^{*} P<0.05$.

$\dagger$ Diabetes was induced by injection of neonatal rats with $90 \mathrm{mg}$ streptozotocin/kg body weight 3 months prior to the experiment. Hot-water extract of $P$. ovata was administered by gavage $(0.5 \mathrm{~g} / \mathrm{kg}$ body weight) twice daily for $28 \mathrm{~d}$. For details of procedures, see $p .132$. 


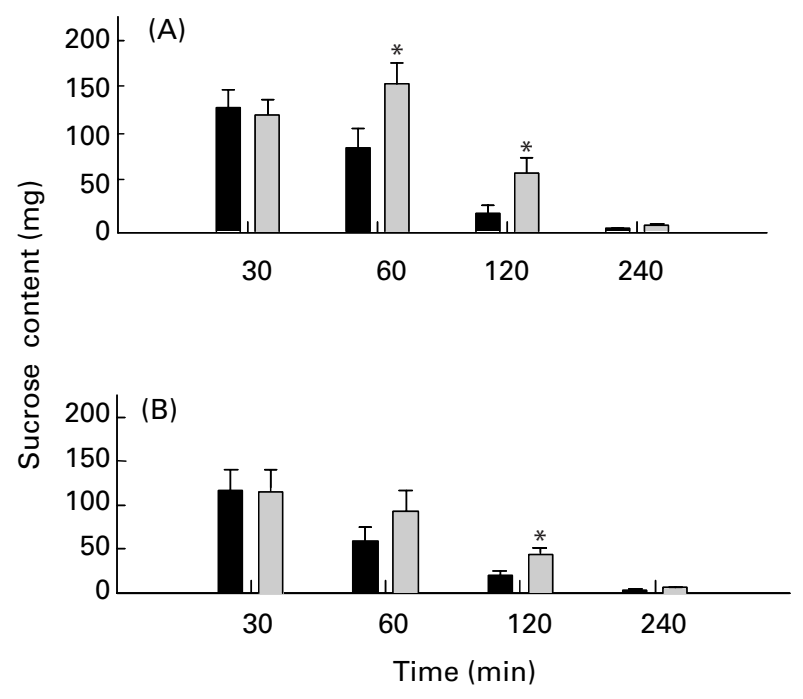

Fig. 3. Effects of hot-water extract of Plantago ovata on gastrointestinal sucrose content after oral sucrose loading in non-diabetic (A) and type 2 diabetic (B) rats. Rats were fasted for $20 \mathrm{~h}$ prior to administration of sucrose solution $(2.5 \mathrm{~g} / \mathrm{kg}$ body weight) by gavage without $(\square)$ or with ( $\square$ ) hot-water extract of $P$. ovata $(0.5 \mathrm{~g} / \mathrm{kg}$ body weight). For details of procedures, see p. 132. Values are means with standard deviations depicted by vertical bars $(n 6)$. Mean values were significantly different from those of the respective control group (repeated measures ANOVA, adjusted using a Bonferroni correction): ${ }^{\star} P<0.05$.

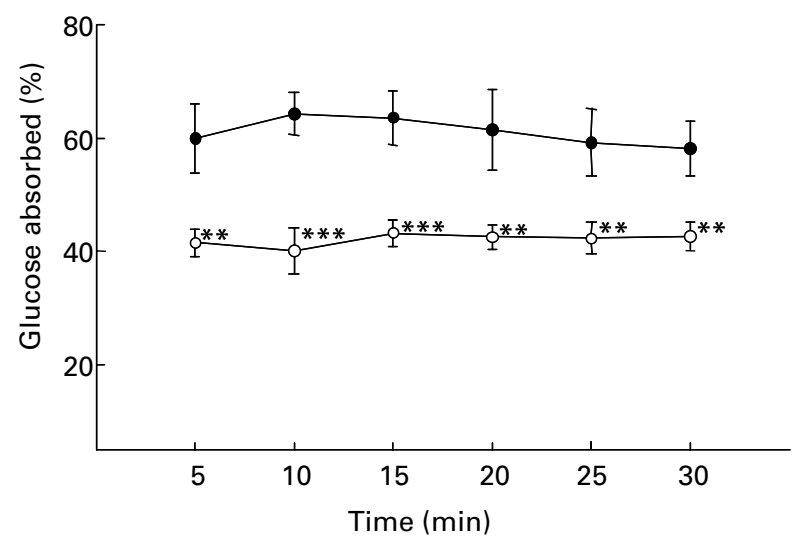

Fig. 4. Effects of hot-water extract of Plantago ovata on intestinal glucose absorption in non-diabetic rats. Rats were fasted for $36 \mathrm{~h}$ and intestine was perfused with glucose $(54 \mathrm{~g} / \mathrm{l})$ with $(0)$ or without $(\bullet)$ hot-water extract of $P$. ovata $(10 \mathrm{mg} / \mathrm{ml})$. For details of procedures, see p. 132. Values are means with standard deviations depicted by vertical bars $(n 6)$. Mean values were significantly different from those of the control group (repeated measures ANOVA, adjusted using a Bonferroni correction): ${ }^{\star \star} P<0.01 ;{ }^{\star \star \star} P<0.001$.

retarding the absorption of ingested carbohydrate. It also served to increase gastrointestinal motility and reduce atherogenic lipids. Thus $P$. ovata may be a useful dietary adjunct for the treatment of hyperglycaemia as well as dyslipidaemia in type 2 diabetes.

\section{References}

Abraham ZD \& Mehta T (1988) Three-week psyllium husk supplementation: effect on plasma cholesterol concentrations, fecal steroid excretion, and carbohydrate absorption in men. Am J Clin Nutr 47, 67-74.
Anderson JW, Allgood LD, Turner J, Oeltgen PR \& Daggy BP (1999) Effects of psyllium on glucose and serum lipid responses in men with type 2 diabetes and hypercholesterolemia. Am J Clin Nutr 70, 466-473.

Bonner-Weir S, Trend DF, Honey RN \& Weir GC (1981) Responses of neonatal rat islets to streptozotocin: limited B-cell regeneration and hyperglycemia. Diabetes 30, 64-69.

Burton R \& Manninen V (1982) Influence of a psyllium-based fibre preparation on faecal and serum parameters. Acta Med Scand 668, S91-S94.

Caspary W \& Creutzfeld W (1971) Analysis of inhibitory effect of biguanides on glucose absorption: inhibition of active sugar transport. Diabetologia 7, 379-385.

Ceriello A, Taboga C, Tonutti L, Giacomello R, Stel L, Motz E \& Pirisi M (1996) Post-meal coagulation activation in diabetes mellitus: the effect of acarbose. Diabetologia 39, 469-473.

Chandalia M, Garg A, Lutjohann D, Bergmann K, Grundy SM \& Brinkle LJ (2000) Beneficial effects of high dietary fiber intake in patients with type 2 diabetes mellitus. N Engl J Med 342, 1392-1398.

Chopra RN, Nayar SL \& Chopra IC (1986) Glossary of Indian Medicinal Plants (including the supplement). New Delhi: Council of Scientific and Industrial Research.

Davis SN \& Granner DK (1996) Insulin, oral hypoglycaemic agents, and the pharmacology of endocrine pancreas. In Goodman and Gilman's The Pharmacological Basis of Therapeutics, 9th ed., pp. 1503 [JG Hardmen and LE Limbrid, editors]. New York: McGraw-Hill.

DeFronzo RA (1992) Pathogenesis of type 2 diabetes mellitus: a balance overview. Diabetologia 35, 389-397.

Everson GT, Daggy BP, McKinley C \& Story JA (1992) Effects of psyllium hydrophilic mucilloid on LDL-cholesterol and bile acid synthesis in hypercholesterolemic men. J Lipid Res 33, 1183-1192.

Fernandez ML, Ruiz LR \& Conde AK (1995) Psyllium reduces plasma LDL in guinea pigs by altering hepatic cholesterol homeostasis. J Lipid Res 36, 1128-1138.

Foster DW (1994) Diabetes mellitus. In Harrison's Principles of Internal Medicine, pp. 1979-1981 [KJ Isselbacher, E Brawnwald, JD Wilson, JB Martin, AS Fauci and DL Kasper, editors]. New York: McGraw-Hill.

Frost SC \& Lane MD (1985) Evidence for the involvement of vicinal sulfhydryl groups in insulin-activated hexose transport by 3T3-L1 adipocytes. J Biol Chem 260, 2646-2652.

Fukagawa NK, Anderson JW \& Hageman G (1990) Highcarbohydrate, high-fibre diets increase peripheral insulin sensitivity in healthy young and old adults. Am J Clin Nutr 52, $524-528$.

Giroix MH, Portha B, Kergoat M, Bailbe D \& Picon L (1983) Glucose insensitivity and amino-acid hypersensitivity of insulin release in rats with non-insulin-dependent diabetes: a study with the perfused pancreas. Diabetes 32, 445-451.

Goto Y, Yamada K, Ohyama T, Matsuo T, Odaka H \& Ikeda H (1995) An alpha-glucosidase inhibitor, AO-128, retards carbohydrate absorption in rats and humans. Diabetes Res Clin Pract 28, 81-87.

Haller H (1997) Postprandial glucose and vascular disease. Diabet Med 14, S50-S56.

Hanefeld MFS, Schulze J, Spengler M, Wargenau M, Schollberg K \& Fucker K (1991) Therapeutic potential of acarabose as first-line drug in NIDDM insufficiently treated with diet alone. Diabetes Care 14, 732-737.

Hannah JS \& Howard BV (1994) Dietary fats, insulin reistance and diabetes. J Cardiovasc Risk 1, 31-37.

King GL, Ishi H \& Koya D (1997) Diabetic vascular dysfunction: a model of excess activation of protein kinase C. Kidney Int 52, S77-S85.

Laakso M \& Lehto S (1997) Epidemiology of macrovascular disease in diabetes. Diabetes Rev 5, 294-315. 
Lembcke B (1987) Control of absorption: delaying absorption as a therapeutic principle. In Structure and Function of the Small Intestine, pp. 263-280 [WF Caspary, editor]. Amsterdam: Excerpta Medica.

Lorch E (1971) Inhibition of intestinal absorption and improvement of oral glucose tolerance by biguanides in the normal and in the streptozotocin diabetic rat. Diabetologia 7, 195-203.

Lupi R, Dotta F, Marselli L, Del Guerra S, Masini M \& Santangelo C (2002) Prolonged exposure to free fatty acids has cytostatic and pro-apoptotic effects on human pancreatic islets: evidence that $\beta$ cell death is caspase mediated, particularly dependent on ceramide pathway and Bcl-2 regulated. Diabetes 51, 1437-1442.

McClenaghan NH, Barnett CR, Ah-Sing E, Abdel-Wahab YH, O'Harte FP, Yoon TW, Swanston-Flatt SK \& Flatt PR (1996) Characterization of a novel glucose-responsive insulin-secreting cell line, BRIN-BD11, produced by electrofusion. Diabetes 45, 1132-1140.

Maedler K, Spinas GA, Dyntar D, Moriz W, Kaiser N \& Donath MY (2001) Distinct effects of saturated and monounsaturated fatty acids on $\beta$ cell turnover and function. Diabetes 50, 69-76.

Marteau P, Flourie B, Cherbut C, Correze JL, Pellier P, Seylaz J \& Rambaud JC (1994) Digestibility and bulking effect of ispaghula husks in healthy humans. Gut 35, 1747-1752.

Mehta KG, Modi R \& Gupta R (1976) Psyllium. Indian J Agron 21, 509-510.

Moskalewski S (1969) Studies the culture and transplantation of isolated islets of langerhans of the guinea pig. Proc K Ned Akad Wet C 72 , $157-171$.

Nutall FO (1993) Dietary fibre in the management of diabetes. Diabetes 42, 503-508.

Prentki M, Vischer S, Glennon MC, Regazzi R, Deeney JT \& Corkey BE (1992) Malonyl-CoA and long chain esters as metabolic coupling factors in nutrient-induced insulin secretion. $J$ Biol Chem 267, $5802-5810$.

Romero AL, Romero JE, Galviz S \& Fernandez ML (1998) Cookies enriched with psyllium or oat bran lower plasma LDL cholesterol in normal and hypercholesterolemic men from Northern Mexico. J Am Coll Nutr 17, 601-608.

Swanston-Flatt SK, Day C, Flatt PR \& Bailey CJ (1991) Evaluation of the antihyperglycaemic properties of traditional plant treatments for diabetes. In Frontiers in Diabetes Research: Lessons from Animal Diabetes, vol. 3, pp. 286-293 [E Shafrir, editor]. London: Smith-Gordon and Company.

Swintosky JV \& Pogonowskawala E (1982) The in-situ rat gut technique. Pharm Int 3, 163-167.

Terpstra AH, Lapre JA, de Vries HT \& Beynen AC (2000) Hypocholesterolemic effect of dietary psyllium in female rats. Ann Nutr Metab 44, 223-228.

Thornalley PJ (1996) Advanced glycation and the development of diabetic complications: unifying the involvement of glucose, methylglyoxal and oxidation stress. Endocrinol Metab 3, 149-166.

Upadhayay VP \& Pandey K (1984) Ayurvedic approach to diabetes mellitus and its management by indigenous resources. In Diabetes Mellitus in Developing Countries, pp. 375-377 [JS Bajay, editor]. New Delhi: Blackwell Publishing.

Vague P (2003) Is metformin more than an oral hypoglycaemic agent? Diabetes Metab 29, 6S5-6S7.

Vander Vries J (1954) Two methods for the determination of glycogen in liver. Biochem $J$ 57, 410-416.

Vinik AL \& Jenkins DJA (1988) Dietary fibre in management of diabetes. Diabetes Care 11, 160-173.

Vinik AL \& Wing RR (1990) Dietary fibre in management of diabetes. In Diabetes mellitus: Theory and Practice, 2nd ed., pp. 465-497 [H Rifkin and D Porte Jr., editors]. New York: Elsevier.

Warier PK (1995) O basilicum Linn. In Indian Medicinal Plants, pp. 160-163 [PK Warrier, VPK Nambia and C Ramankutty, editors]. Madras: Orient Longman.

Washington N, Harris M, Mussellwhite A \& Spiller RC (1998) Moderation of lactulose-induced diarrhea by psyllium: effects on motility and fermentation. Am J Clin Nutr 67, 317-321.

Wolever TM, Vuksan V, Eshuis H, Spadafora P, Peterson RD, Chao ES, Storey ML \& Jenkins DJ (1991) Effect of method of administration of psyllium on glycemic response and carbohydrate digestibility. J Am Coll Nutr 10, 364-371.

Zhou YP \& Grill V (1995) Long-term exposure to fatty acids and ketones inhibits B cell functions in human pancreatic islets of Langerhans. J Clin Endocrinol Metab 80, 1584-1590. 